\title{
In pursuit of an allosteric human tropomyosin kinase A inhibitor ( $h$ TrkA) for chronic pain
}

Govindan Subramanian, ${ }^{*}$ B Brian Duclos,,$\star \uparrow$ Paul D. Johnson, Tracey Williams, Jason T. Ross, Scott

J. Bowen, Yaqi Zhu, Julie A. White, Carolyn Hedke, Dennis Huczek, Wendy Collard, Christopher Javens, Rajendran Vairagoundar, Tomasz Respondek, Theresa Zachary, Todd Maddux, Mark R Cox, Steven Kamerling, and Andrea J. Gonzales*

Veterinary Medicine Research \& Development, Zoetis, 333 Portage Street, Bldg. 300, Kalamazoo, MI 49007, U.S.A.

\section{Supporting Information}

* Corresponding author. Tel.: +1-269-359-9528; e-mail: govindan.subramanian@zoetis.com; e-mail: andrea.gonzales@zoetis.com.

$\$$ These authors contributed equally to the work. + Medtronic, 7000 Central Ave NE., Minneapolis, MN55432, U.S.A. 


\section{Table of Contents}

$\begin{array}{ll}\text { Chemical Synthesis } & \text { S3 }\end{array}$

Reaction scheme $\quad S 4$

Synthesis of $1 \quad$ S5

$\begin{array}{ll}\text { In vitro profile of } 1 & \mathrm{~S} 10\end{array}$

In vitro evaluation (TR-FRET) of the effect of 1 on the human TrkA enzyme S10

In vitro evaluation (Caliper) of the effect of 1 on the human TrkA enzyme. S11

In vitro evaluation of the effect of $\mathbf{1}$ in a cell-based receptor tyrosine kinase

functional assay $\quad \mathrm{S} 12$

In vitro evaluation of single-cycle kinetics (SCK) binding of 1 Using a Biacore T200 S12

In vitro evaluation of the effect of 1 on rat PC12 cell neurite outgrowth assay $\mathrm{S} 15$

In vitro evaluation of the effect of 1 in rat PC12 cell using label free CETSA assay S16

\section{X-ray structure of $h \operatorname{TrkA} \ldots 1$ bound kinase complex}

Data collection, processing, and refinement statistics for $h$ TrkA...1

bound kinase complex

S18

Animal Experiments

S21

Ex vivo immunohistochemical detection of TrkA in the dorsal root ganglion and spinal cord of rats treated intra-articularly with monoiodoacetate (MIA).

Effect of 1 in a monoiodoacetate (MIA) rat model of osteoarthritis 


\section{Chemical synthesis}

\section{General considerations}

All reagents were purchased from commercial suppliers and used as received. Solvents were purchased from EMD Millipore Corporation as DriSolv (> 99.8\%). NMR spectra were recorded on a Bruker FT-NMR $400 \mathrm{MHz}$ Spectrometer. Chemical shifts are reported in ppm with the solvent resonance as the internal standard. Data are reported as follows: chemical shift, multiplicity $(\mathrm{s}=$ singlet, $\mathrm{d}=$ doublet, $\mathrm{t}=$ triplet, $\mathrm{q}=$ quartet, $\mathrm{m}=$ multiplet, $\mathrm{br}$ = broad), coupling constant $(\mathrm{Hz})$ and integration. LC/MS data was acquired on an Agilent 1200 Series LC/MS system equipped with an Agilent 6140 Single Quadrupole mass spectrometer and a Waters BEH C8 1.7um 2.1×50 mm column. Reactions were monitored using LC/MS or TLC (EMD Millipore TLC Silica gel $60 \mathrm{~F}_{254}$ plates). Microwave reactions were performed using a CEM Discover reactor. Flash chromatography was performed with an automated system using prepackaged columns from Biotage or Teledyne Isco. All reactions were performed under ambient atmosphere unless otherwise noted. Anaerobic reactions were performed by purging the reaction solutions with Ar or $\mathrm{N}_{2}$. 


\section{Reaction Schemes}
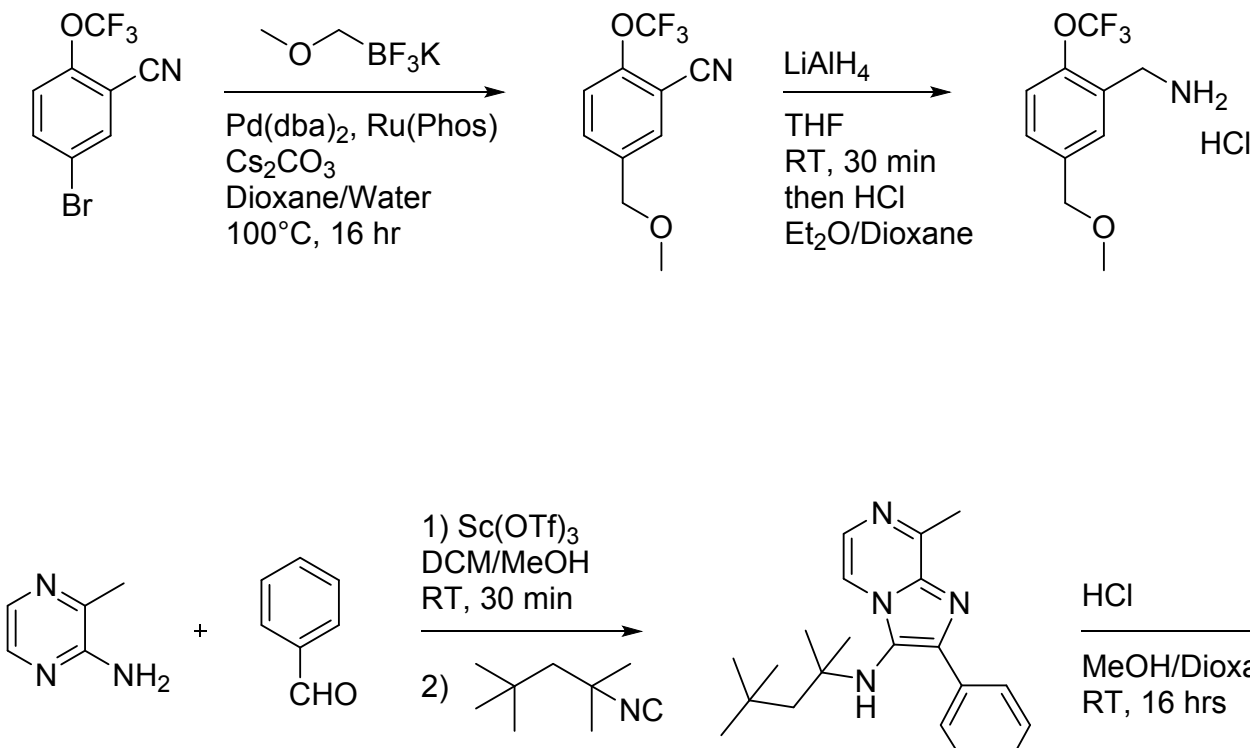

RT, 16 hrs

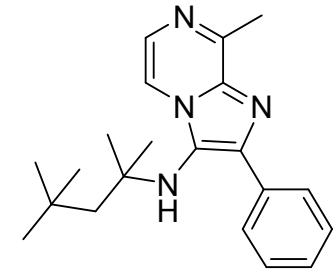

$\mathrm{HCl}$

$\mathrm{MeOH} /$ Dioxane

RT, 16 hrs

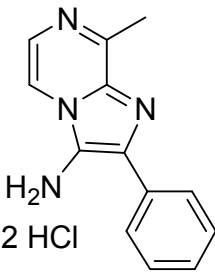

1) CDI, DIPEA

$\mathrm{MeCN}$<smiles>Cc1nccn2c(N)c(-c3ccccc3)nc12</smiles>

$75^{\circ} \mathrm{C}, 2.5 \mathrm{hrs}$

2)<smiles>COCc1ccc(OC(F)(F)F)c(CN)c1</smiles><smiles>COCc1ccc(OC(F)(F)F)c(CNC(=O)Nc2c(-c3ccccc3)nc3c(C)nccn23)c1</smiles>

RT, $1 \mathrm{hr}$ 
Synthesis of 1

(5-(methoxymethyl)-2-(trifluoromethoxy)phenyl)methanamine hydrochloride

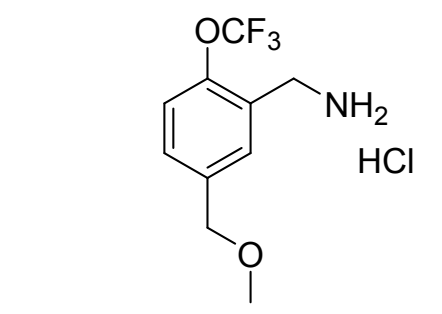

Chemical Formula: $\mathrm{C}_{10} \mathrm{H}_{13} \mathrm{ClF}_{3} \mathrm{NO}_{2}$

Exact Mass: 271.06

Molecular Weight: 271.66

The procedure is a modification of the procedure found in WO 2014/078331. ${ }^{1}$

Step A. A mixture of 5-bromo-2-(trifluoromethoxy)benzonitrile (10.00 g. $37.6 \mathrm{mmol}, 1.00$ eq), potassium methoxymethyltrifluoroborate $(7.50 \mathrm{~g}, 48.4 \mathrm{mmol}, 1.29 \mathrm{eq})$, RuPhos (1.75 $\mathrm{g}, 3.76 \mathrm{mmol}, 0.10 \mathrm{eq}), \mathrm{Pd}(\mathrm{dba})_{2}(1.08 \mathrm{~g}, 1.88 \mathrm{mmol}, 0.05 \mathrm{eq})$ and cesium carbonate (35 $\mathrm{g}, 107 \mathrm{mmol}, 2.86 \mathrm{eq})$ was suspended in dioxane $(200 \mathrm{ml})$ and water $(40 \mathrm{~mL}) . \mathrm{N}_{2}$ was bubbled through the solution for $5 \mathrm{~min}$ and the resulting mixture was stirred at $100^{\circ} \mathrm{C}$ for $16 \mathrm{hr}$. After completion of the reaction, the mixture was cooled down, the layers separated and the aqueous layer extracted with ethyl acetate $(2 \times 30 \mathrm{~mL})$. The organic layers were combined, dried over $\mathrm{Na}_{2} \mathrm{SO}_{4}$, and concentrated under reduced pressure to give the crude product. The crude was purified by flash chromatography using 0-20 \% EtOAC in heptane to give 5-(methoxymethyl)-2-(trifluoromethoxy)benzonitrile as an oil (9.00 g). The obtained oily product was stirred with heptane $(25 \mathrm{~mL})$ to give an off white solid that was filtered off and dried under high vacuum $\left(8.30 \mathrm{~g}, 95 \%\right.$ isolated yield). ${ }^{1} \mathrm{H}$ NMR (400 MHz, CHLOROFORM-d) $\delta$ ppm 7. $70(\mathrm{dd}, J=2.20,0.49 \mathrm{~Hz}, 1 \mathrm{H}$ ), $7.59-7.64$ (ddt, $\mathrm{J}=8.56,2.30,0.73,0.73 \mathrm{~Hz}, 1 \mathrm{H}), 7.38(\mathrm{dq}, \mathrm{J}=8.56,1.47 \mathrm{~Hz}, 1 \mathrm{H}), 4.48(\mathrm{~s}, 2 \mathrm{H}), 3.45(\mathrm{~s}$, $3 \mathrm{H})$. LCMS m/z: calculated for $\mathrm{C}_{10} \mathrm{H}_{8} \mathrm{~F}_{3} \mathrm{NO}_{2} 231.1$, found $231.9[\mathrm{M}+\mathrm{H}], \mathrm{RT}=2.90 \mathrm{~min}$. 
Step B. To a solution of 5-(methoxymethyl)-2-(trifluoromethoxy)benzonitrile (1.80 g, 7.79 mmol, $1.00 \mathrm{eq})$ in THF $(20 \mathrm{ml})$ was slowly added a solution of $\mathrm{LiAlH}_{4}(1.0 \mathrm{M}$ in THF, 15.6 $\mathrm{mL}, 15.6 \mathrm{mmol}, 2.0 \mathrm{eq}$ ) at $20^{\circ} \mathrm{C}$. The resulting mixture was stirred for $30 \mathrm{~min}$ at RT. After the completion of the reaction, the reaction mixture was cooled to $0^{\circ} \mathrm{C}$ and carefully quenched with ice -water $(2 \mathrm{~mL})$ followed by ice cold $25 \% \mathrm{NaOH}(3 \mathrm{~mL})$. The resulting mixture was diluted with THF $(15 \mathrm{~mL})$ and stirred for $30 \mathrm{~min}$. The organic layer was separated and the aqueous layer was extracted with DCM $(3 \times 20 \mathrm{~mL})$. The organic layers were combined, dried over $\mathrm{Na}_{2} \mathrm{SO}_{4}$ and concentrated to give the crude product. The crude was purified by flash chromatography using 0 to $10 \%$ methanol in DCM to give the desired product as a free amine (oil, $1.50 \mathrm{~g}$ ). The oil was dissolved in $\mathrm{Et}_{2} \mathrm{O}(20 \mathrm{~mL}$ ) and $4.0 \mathrm{M} \mathrm{HCl}$ in dioxane $(3.25 \mathrm{ml}, 13.0 \mathrm{mmol}, 2.0 \mathrm{eq})$ was added at $0{ }^{\circ} \mathrm{C}$. After stirring for 15 min, the solid was filtered, washed with ether, and dried under vacuum to give (5(methoxymethyl)-2-(trifluoromethoxy)phenyl)methanamine hydrochloride as a white solid (1.50 g, 71\% isolated yield). ${ }^{1} \mathrm{H}$ NMR (400 MHz, DMSO- $\left.d_{6}\right) \delta \mathrm{ppm} 8.80$ (br s, $3 \mathrm{H}$ ), 7.73 (d, J=1.71 Hz, $1 \mathrm{H}), 7.37$ - 7.48 (m, $2 \mathrm{H}), 4.43(\mathrm{~s}, 2 \mathrm{H}), 4.05$ (s, $2 \mathrm{H}), 3.32$ (s, $3 \mathrm{H})$. LCMS $\mathrm{m} / \mathrm{z}$ : calculated for $\mathrm{C}_{10} \mathrm{H}_{12} \mathrm{~F}_{3} \mathrm{NO}_{2} 235.1$, found $236.1[\mathrm{M}+\mathrm{H}], \mathrm{RT}=2.03 \mathrm{~min}$.

\section{8-methyl-2-phenylimidazo[1,2-a]pyrazin-3-amine dihydrochloride}




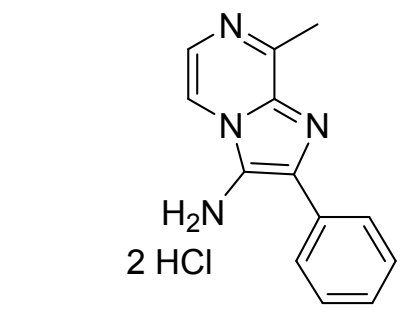

Chemical Formula: $\mathrm{C}_{13} \mathrm{H}_{14} \mathrm{Cl}_{2} \mathrm{~N}_{4}$

Exact Mass: 296.06

Molecular Weight: 297.18

The procedure is an adaptation of the procedure found in WO2014/078408. ${ }^{2}$

Step A. 3-methylpyrazin-2-amine $(9.75 \mathrm{~g}, 89.3 \mathrm{mmol}, 1.00 \mathrm{eq})$ was dissolved in DCM:MeOH (240 mL, 2:1) and benzaldehyde $(9.99 \mathrm{~mL}, 98.2 \mathrm{mmol}, 1.1 \mathrm{eq})$ followed by $\mathrm{Sc}(\mathrm{OTf})_{3}(2.20 \mathrm{~g}, 4.47 \mathrm{mmol}, 0.05 \mathrm{eq}$,$) were added. The resulting solution was stirred at$ RT for 30 min. 2-isocyano-2,4,4-trimethylpentane (18.8 mL, $107 \mathrm{mmol}, 1.2 \mathrm{eq}$,$) was then$ added in one portion and the resulting solution stirred overnight at RT. After the completion of the reaction, the crude mixture was concentrated under reduced pressure and purified by flash chromatography using EtOAc in hexanes from 0 to $100 \%$ to afford 8-methyl-2-phenyl-N-(2,4,4-trimethylpentan-2-yl)imidazo[1,2-a]pyrazin-3-amine (21.14 g, 70.0\% isolated yield). ${ }^{1} \mathrm{H}$ NMR (400 MHz, CHLOROFORM- $d$ ) $\delta p p m 8.10$ (d, $J=4.65 \mathrm{~Hz}$, $1 \mathrm{H}), 7.83(\mathrm{dd}, J=8.19,1.34 \mathrm{~Hz}, 2 \mathrm{H}), 7.76(\mathrm{~d}, J=4.65 \mathrm{~Hz}, 1 \mathrm{H}), 7.43-7.52(\mathrm{~m}, 2 \mathrm{H}), 7.36$ - $7.43(\mathrm{~m}, 1 \mathrm{H}), 3.35$ (br s, $1 \mathrm{H}), 2.98(\mathrm{~s}, 3 \mathrm{H}), 1.56(\mathrm{~s}, 2 \mathrm{H}), 1.00$ - $1.06(\mathrm{~m}, 9 \mathrm{H}), 0.96(\mathrm{~s}$, $6 \mathrm{H}$ ). LCMS m/z: calculated for $\mathrm{C}_{21} \mathrm{H}_{28} \mathrm{~N}_{4} 336.2$, found $337.2[\mathrm{M}+\mathrm{H}], \mathrm{RT}=2.96$

Step B. 8-methyl-2-phenyl-N-(2,4,4-trimethylpentan-2-yl)imidazo[1,2-a]pyrazin-3-amine (2.30 g, $6.82 \mathrm{mmol}, 1.00 \mathrm{eq}$ ) was dissolved in $\mathrm{MeOH}(15 \mathrm{~mL})$ at $0^{\circ} \mathrm{C}$ and $\mathrm{HCl}$ in Dioxane (4.0 M, $34.1 \mathrm{~mL}, 136 \mathrm{mmol}, 20.0 \mathrm{eq})$ was added and the resulting solution was stirred at RT for 16 hours. After completion of the reaction, MTBE $(125 \mathrm{~mL})$ was added and the resulting solution stirred for 15 min, during which a bright yellow solid starting to 
precipitate out. The solid was filtered off, washed with more MTBE, dried under high vacuum to give 8-methyl-2-phenylimidazo[1,2-a]pyrazin-3-amine dihydrochloride (1.74 g, $86 \%$ isolated yield). ${ }^{1} \mathrm{H}$ NMR (400 MHz, DMSO-d6) $\delta p p m ~ 8.39(\mathrm{~d}, \mathrm{~J}=5.62 \mathrm{~Hz}, 1 \mathrm{H}), 8.01$ (dd, J=8.44, 1.35 Hz, 2 H), $7.76(d, J=5.62$ Hz, 1 H), 7.52 - $7.59(m, 2$ H), 7.42 - $7.49(m$, $1 \mathrm{H}), 7.09$ (br s, $2 \mathrm{H}), 2.85(\mathrm{~s}, 3 \mathrm{H})$. LCMS m/z: calculated for $\mathrm{C}_{13} \mathrm{H}_{12} \mathrm{~N}_{4} 224.1$, found $225.2[\mathrm{M}+\mathrm{H}], \mathrm{RT}=1.92 \mathrm{~min}$.

\section{1-(5-(methoxymethyl)-2-(trifluoromethoxy)benzyl)-3-(8-methyl-2-phenylimidazo [1,2-a]pyrazin-3-yl)urea}

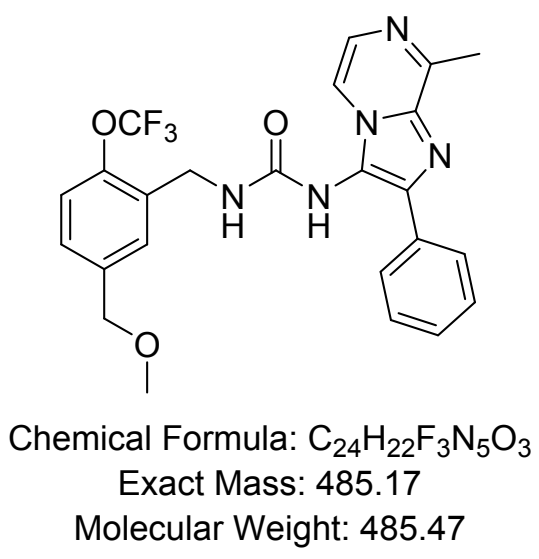

8-methyl-2-phenylimidazo[1,2-a]pyrazin-3-amine dihydrochloride (1.00 g, 1.00 eq, 3.365 mmol) was suspended in $\mathrm{MeCN}(100 \mathrm{~mL})$ in a $350 \mathrm{~mL}$ pressure flask and CDI (1.809 g, $10.94 \mathrm{mmol}, 3.25 \mathrm{eq}$ ) was added followed by DIPEA (4.00 eq, $2.36 \mathrm{~mL}, 13.5 \mathrm{mmol}$ ) upon which all solids went into solution within seconds. The resulting solution was stirred at $75^{\circ} \mathrm{C}$ for $2.5 \mathrm{hrs}$. Upon completion of the isocyanate intermediate formation, the solution was cooled to RT over $15 \mathrm{~min}$. (5-(methoxymethyl)-2-(trifluoromethoxy)phenyl) methanamine hydrochloride (1.2 eq, $1.097 \mathrm{~g}, 4.038 \mathrm{mmol})$ was added and the resulting solution was stirred at RT for 15 min at which point some white material has started precipitating from the reaction mixture. The flask was moved to a freezer and left at - 
$20^{\circ} \mathrm{C}$ overnight. The next day the solids were filtered, washed with $20 \mathrm{~mL}$ cold $\mathrm{MeCN}$, then $\mathrm{Et}_{2} \mathrm{O}$ and dried under reduced pressure (1.12 $\mathrm{g}$ of material collected). The mother liquors were concentrated under reduced pressure and purified by flash chromatography on silica with $\left(\mathrm{MeOH} / 2.0 \mathrm{M} \mathrm{NH}_{3}\right)$ in $\mathrm{DCM}$ from 0 to $10 \%$ to give $0.85 \mathrm{~g}$ of a yellow oil. The oil was dissolved in $\sim 3.0 \mathrm{~mL}$ hot $\mathrm{MeCN}$ and the vial was placed in the freezer overnight. The next day the white solids were filtered, washed with $20 \mathrm{~mL}$ cold $\mathrm{MeCN}$, then $\mathrm{Et}_{2} \mathrm{O}$ and dried under reduced pressure (additional $0.31 \mathrm{~g}$ collected). The solids from both recrystallization cycles were combined to give 1-(5-(methoxymethyl)-2(trifluoromethoxy)benzyl)-3-(8-methyl-2-phenylimidazo[1,2-a]pyrazin-3-yl)urea (1.43 g, $87 \%$ yield). ${ }^{1} \mathrm{H}$ NMR (400 MHz, DMSO- $\left.d_{6}\right) \delta$ ppm $8.69(\mathrm{~s}, 1 \mathrm{H}), 8.05$ (d, J=7.34 Hz, $2 \mathrm{H}$ ), $7.97(\mathrm{~d}, \mathrm{~J}=4.65 \mathrm{~Hz}, 1 \mathrm{H}), 7.79(\mathrm{~d}, \mathrm{~J}=4.65 \mathrm{~Hz}, 1 \mathrm{H}), 7.45-7.52(\mathrm{~m}, 2 \mathrm{H}), 7.38-7.44(\mathrm{~m}, 1$ H), 7.33 (br s, 1 H), 7.31 (s, 2 H), 7.23 (br s, 1 H), 4.37 (br s, 2 H), 4.34 (br s, 2 H), 2.78 (s, $3 \mathrm{H}$ ). LCMS m/z: calculated for $\mathrm{C}_{24} \mathrm{H}_{22} \mathrm{~F}_{3} \mathrm{~N}_{4} \mathrm{O}_{3} 485.2$, found $486.0[\mathrm{M}+\mathrm{H}], \mathrm{RT}=2.73$ $\min$. 


\section{In vitro profile of 1}

$h$ Trk inhibitor compounds were dissolved in dimethylsulfoxide (DMSO) (Sigma) at a concentration of $30 \mathrm{mM}$. Subsequent dilutions were made in assay buffer with an inert maximal final concentration of $0.216 \%$ DMSO for the cell based Pathhunter (DiscoverX) assay. For the cell-free kinase assay, compound dilutions were made in kinase buffer (Cisbio) with a maximal final concentration of $0.25 \%$ DMSO.

In vitro evaluation (TR-FRET) of the effect of 1 on the human TrkA enzyme. The chemical series to which 1 belongs was initially evaluated using a high throughput, hTrkA time-resolved fluorescence energy transfer (TR-FRET) enzyme assay, whereby the TR-FRET signal is proportional to the enzymatic substrate phosphorylation. The TrkA enzymatic activity assay was carried out in a 384-well plate (Greiner). Human TrkA kinase (NTRK1 gene; Invitrogen) was used for the enzymatic assay. Homogeneous time resolved fluorescence (HTRF) KinEASE kit (Cisbio) was used for kinase reaction and detection. $5 \mathrm{X}$ kinase buffer was diluted to $1 \mathrm{X}$ in distilled water with $2 \mathrm{mM}$ dithiothreitol (DTT) and $10 \mathrm{mM} \mathrm{MgCl}_{2}$. This $1 \mathrm{X}$ enzyme buffer was used for enzyme, substrate and compound dilution. TrkA enzyme (non-ATP activated; $3 \mathrm{nM}$ final assay concentration) and compound (5 $\mu \mathrm{M}$ final assay concentration for top dose of 11 point dilution) were added in the plate and incubated for 20 minutes at room temperature (RT). Tyrosine kinase (TK) substrate (0.3 $\mu \mathrm{M}$ final assay concentration) with ATP (225 $\mu \mathrm{M}$ final assay concentration) were then added to the plate and incubated for 1 hour at RT. The detection mix was prepared in detection buffer by adding TK-cryptate (1:200 dilution) and Streptavidin- XL665 (37.5 nM). Freshly prepared detection mix was added to all the wells, incubated for 1 hour at RT and the plate read in an Envision multimode reader (PerkinElmer) with excitation at $320 \mathrm{~nm}$ and emission at $615 \mathrm{~nm} / 665$ 
$\mathrm{nm}$. Blanks were prepared by addition of DMSO (0.25\% final assay concentration). All assays were performed in triplicate in at least two separate experiments. The raw data generated was

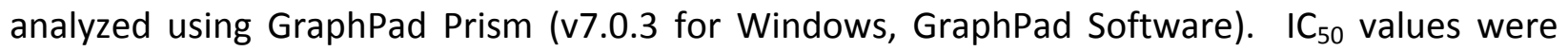
determined using a four-parameter logistic equation from the percent inhibition values plotted against the logarithmic concentration of the compound.

In vitro evaluation (Caliper) of the effect of 1 on the human TrkA enzyme. A Caliper LC3000 instrument (PerkinElmer) with a LabChip EZ-Reader 12-sipper chip (PerkinElmer) was used to separate and quantify the peptide substrate and phospho-peptide reaction product to study inhibition of $h$ TrkA and determine enzyme phosphorylation-state binding. The separation buffer contained 100 mM HEPES, 10 mM EDTA, 0.0005\% Tween 20, 0.1\% Coating Reagent 3 (PerkinElmer), and 1\% DMSO, with a downstream voltage of -800 , upstream voltage of -2750 , and screen pressure of -1.1 psi. Inactive TrkA (Life Technologies) was activated by incubating 1 $\mu \mathrm{M}$ inactive TrkA with $2 \mathrm{mM}$ ATP in assay buffer (20 mM HEPES, pH 7.4, $10 \mathrm{mM} \mathrm{MgCl}, 0.01 \%$ BSA, $0.0005 \%$ Tween 20, 1 mM DTT) at RT for 2 hours. $80 \mathrm{~nL}$ of compound or DMSO control was added to the assay plate (Axygen/Corning) in duplicate 11-point dose response curves with 3fold changes in concentration between doses. TrkA enzyme $(20 \mu \mathrm{L})$ was added and incubated for 20 minutes at RT before addition of $20 \mu \mathrm{L}$ ATP and CSKtide (Anaspec) mixture. Final concentrations (in assay buffer) were 0.2\% DMSO, $1 \mu \mathrm{M}$ CSKtide, $100 \mu \mathrm{M}$ ATP, 0.5 or $1 \mathrm{nM}$ active TrkA or $20 \mathrm{nM}$ inactive TrkA, and variable amounts of compound. After 2 hours at RT reactions were terminated by the addition of $40 \mu \mathrm{L}$ of stop buffer ( $20 \mathrm{mM}$ HEPES, pH 7.4, $30 \mathrm{mM}$ EDTA) and the phospho-peptide product quantified on the Caliper LC3000. Under these conditions, there was typically $20 \%-30 \%$ conversion of substrate to product in the absence of inhibitor. 
Results were expressed as percent inhibition relative to no enzyme and no inhibitor controls and $\mathrm{IC}_{50}$ values calculated using GraFit software (Erithacus Software Limited). For incomplete Scurves, plateaus were fixed at either $100 \%$ or $0 \%$ inhibition.

In vitro evaluation of the effect of 1 in a cell-based receptor tyrosine kinase functional assay. The TrkA and TrkB cell-based assays were carried out in a 384-well plate (Greiner) using PathHunter ${ }^{\circledR}$ (DiscoverX) U2OS TrkA and TrkB cells. These cell lines are engineered to co-express a ProLink ${ }^{\mathrm{TM}}$ tagged receptor tyrosine kinase (RTK), with an enzyme acceptor (EA) tagged SH2 domain. Activation of the RTK- ProLink ${ }^{\mathrm{TM}}$ induces receptor dimerization, leading to SH2-EA recruitment, and forcing complementation of the two $\beta$-galactosidase enzyme fragments (EA and ProLink $\left.^{\mathrm{TM}}\right)$. The resulting functional enzyme hydrolyzes substrate to generate a chemiluminescent signal. Briefly, 10,000 cells/well were seeded on the day before assay in serum free MEM (GIBCO) and incubated for 16 hours at $37^{\circ} \mathrm{C}$ and $5 \% \mathrm{CO}_{2}$. Trk inhibitor compounds (diluted in PBS containing $0.05 \%$ Pluronic acid, $\mathrm{pH}$ 7.4) were added in the assay plate at a final concentration of $5 \mu \mathrm{M}$ (top dose of 11-point dilution) and incubated at RT for 30 minutes. Agonists (NGF for TrkA and BDNF for TrkB; Peprotech) were added in the assay plate at $\mathrm{EC}_{80}$ concentration and incubated for 2 hours at RT. The agonists were diluted in PBS containing $0.25 \%$ BSA, pH 7.4. PathHunter ${ }^{\circledR}$ (DiscoverX) detection mix (prepared as per kit protocol) was added in the assay plate and incubated at RT for 1 hour. Luminescence counts were taken in SpectraMax M5 (Molecular Devices Inc) with exposure time of 1 second per well.

In vitro evaluation of single-cycle kinetics (SCK) binding of 1 Using a Biacore T200. $40 \mu \mathrm{g} / \mathrm{ml}$ each of ATP treated (Carna Biosciences Inc) and non-ATP treated (Carna Biosciences Inc) 
biotinylated-TrkA were captured on a streptavidin (SA) sensor at $4^{\circ} \mathrm{C}$ in freshly prepared, precooled TTNM buffer (50 mM Tris-HCL pH 7.5, 0.05\% P20, $150 \mathrm{mM} \mathrm{NaCl}$ and $5 \mathrm{mM} \mathrm{MgCl} 2$ ) with a flow rate of $10 \mu \mathrm{l} / \mathrm{min}$ and a goal of $6000 \mathrm{RU}$ surface density. $10 \mu \mathrm{g} / \mathrm{ml}$ of biocytin was then injected $3 \times 60$ seconds at a flow rate of $10 \mu \mathrm{l} / \mathrm{min}$ to block remaining SA. The temperature was then raised to $22^{\circ} \mathrm{C}$ and pre-run TTNM with $1 \%$ DMSO until the surface was stable. Compounds were diluted to final concentrations in TTNM buffer with $1 \%$ DMSO. Compounds were tested at $0.078,0.31,1.25,5$ and $20 \mu \mathrm{M}$ with 100 seconds contact time and 1200 seconds dissociation time at a flow rate of $30 \mu \mathrm{l} / \mathrm{min}$. TTNM buffer with $1 \%$ DMSO was also injected before every cycle as a reference control. Data was analyzed using the Biacore T200 Evaluation software v3.1 (Cytiva) by $1: 1$ binding, and residence time $(\tau)$ was then calculated based on dissociation rate (Fig. S1 bottom).

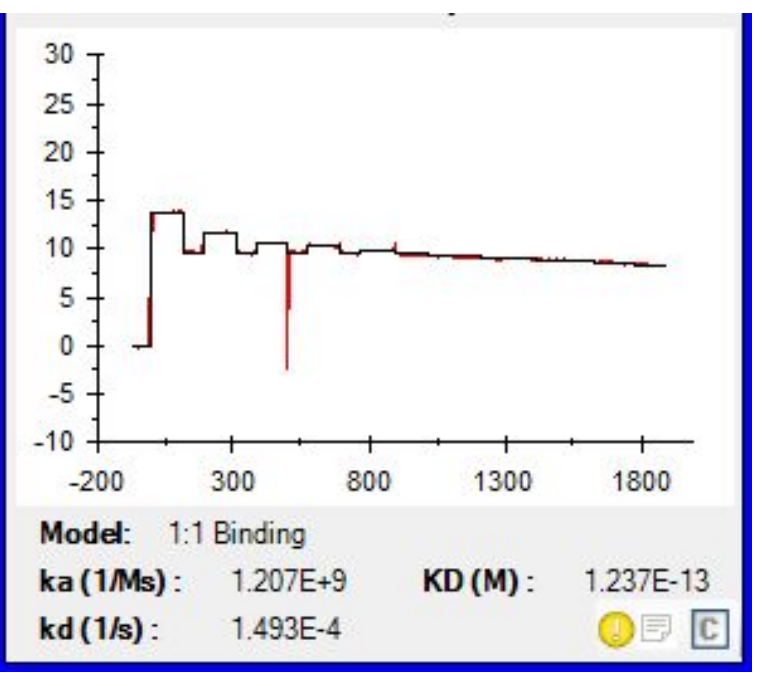

AZ-23 (active enzyme)

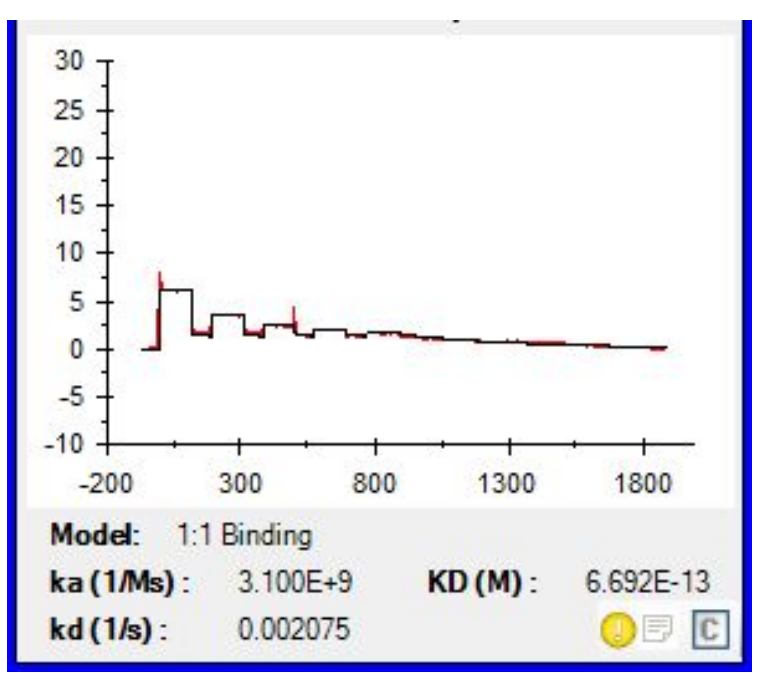

AZ-23 (inactive enzyme) 


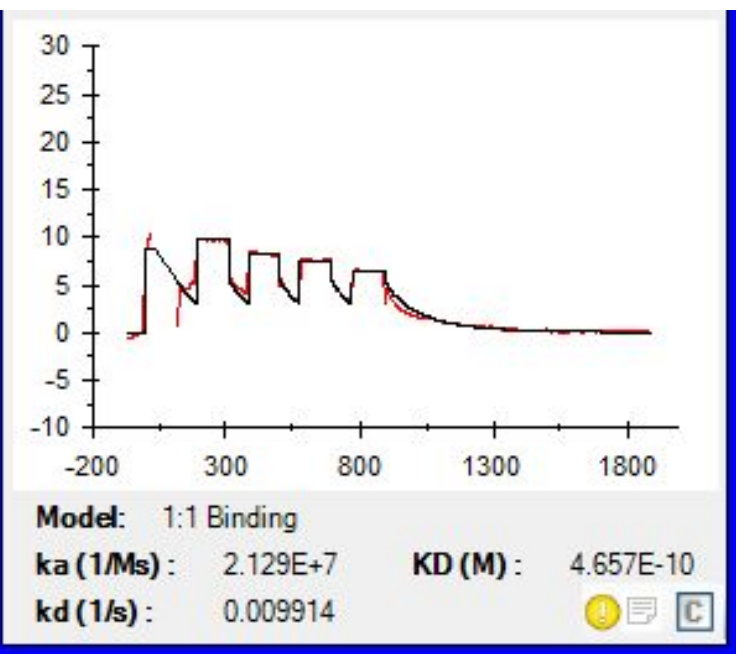

1 (active enzyme)

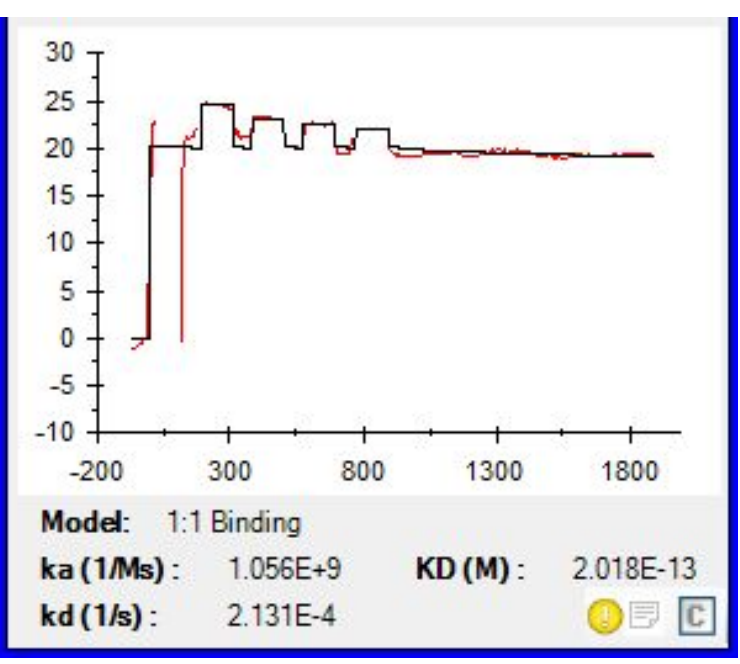

1 (inactive enzyme)

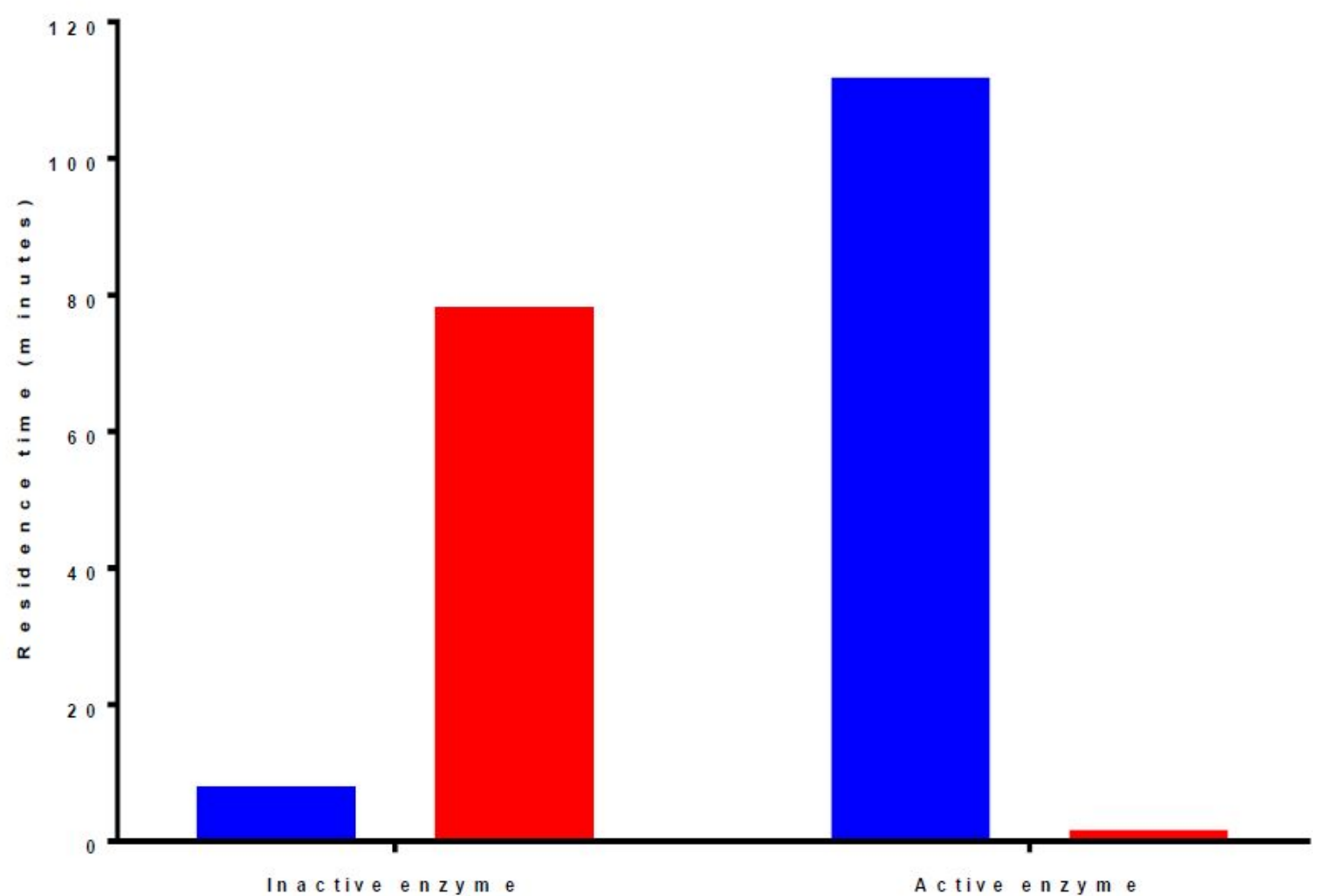

Figure S1. Single-cycle kinetics binding of 1 (red) and AZ-23 (blue) using a Biacore T200. ATP treated (active) and non-ATP treated (inactive) biotinylated-TrkA were captured on a SA sensor with a flow rate of $10 \mu \mathrm{l} / \mathrm{min}$ to reach $6000 \mathrm{RU}$ surface density. Compounds were tested at $0.078,0.31,1.25,5$ and $20 \mu \mathrm{M}$ with 100 seconds contact time and 1200 seconds dissociation time at a flow rate of $30 \mu \mathrm{l} / \mathrm{min}$ and residence time $(\tau)$ was then calculated based on dissociation rate. 
In vitro evaluation of the effect of 1 on rat PC12 cell neurite outgrowth assay. TrkA inhibitors were evaluated for functional potency in a neurite outgrowth assay utilizing rat PC12 cells (CRL1721, American Type Culture Collection (ATCC), Rockville, MD) which express both TrkA and its co-receptor p75.

PC12 cells $^{3}$ were maintained in ATCC modified RPMI 1640 medium (Life Technologies) supplemented with $5 \%$ fetal bovine serum (FBS; Life Technologies) and $10 \%$ heat-inactivated horse serum (HI-HS; Life Technologies) and incubated at $37^{\circ} \mathrm{C}$ and $5 \% \mathrm{CO}_{2}$. On the day of experiment, PC12 cells were removed from culture flasks with a cell scraper (Corning) and cell suspension was centrifuged at $200 \times \mathrm{g}$ for 10 minutes. After centrifugation, supernatant was discarded, and the cell pellet resuspended in $5 \mathrm{~mL}$ assay medium: ATCC modified RPMI 1640 supplemented with $1 \% \mathrm{HI}-\mathrm{HS}, 0.5 \% \mathrm{FBS}$, and $10 \mu \mathrm{g} / \mathrm{ml}$ gentamicin. Resulting cell suspension was gently triturated $15-20$ times with a $10 \mathrm{~mL}$ syringe outfitted with a 22 gauge $x 1.5$ inch needle (Becton Dickinson) to break up cell clusters before counting and further dilution of suspension. The PC12 neurite outgrowth assay was performed in collagen IV coated 96 well microplates (Corning) by preincubating 3,000 cells per well with TrkA inhibitors (solubilized in DMSO), at concentrations indicated, for 30 minutes before adding $50 \mathrm{ng} / \mathrm{ml}$ recombinant rat $\beta$-NGF (R\&D Systems). Final DMSO concentration in the assay was $0.1-0.25 \%$.

After a 7-day culture period at $37^{\circ} \mathrm{C}$ with $5 \% \mathrm{CO}_{2}$, an IncuCyte $\mathrm{ZOOM}$ live-cell imaging system V2015A;rev 1 (Essen Bioscience, Inc.) was employed to evaluate the effects of TrkA inhibitors on rat $\beta$-NGF induced neurite outgrowth. To assess neurite outgrowth, each well was imaged at $10 x$ magnification and the summed length of neurites extending from cell bodies was quantitated 
(millimeter/cell-body cluster) using IncuCyte NeuroTrack software module (Essen Bioscience, Inc.). Results are expressed as percent inhibition relative to \pm NGF controls without inhibitor. Calculated percent inhibition data were analyzed with GraphPad Prism v7.0.3 (GraphPad Software Inc.) for $\mathrm{IC}_{50}$ determination using a 4-parameter logistic curve fit (Fig. S2).

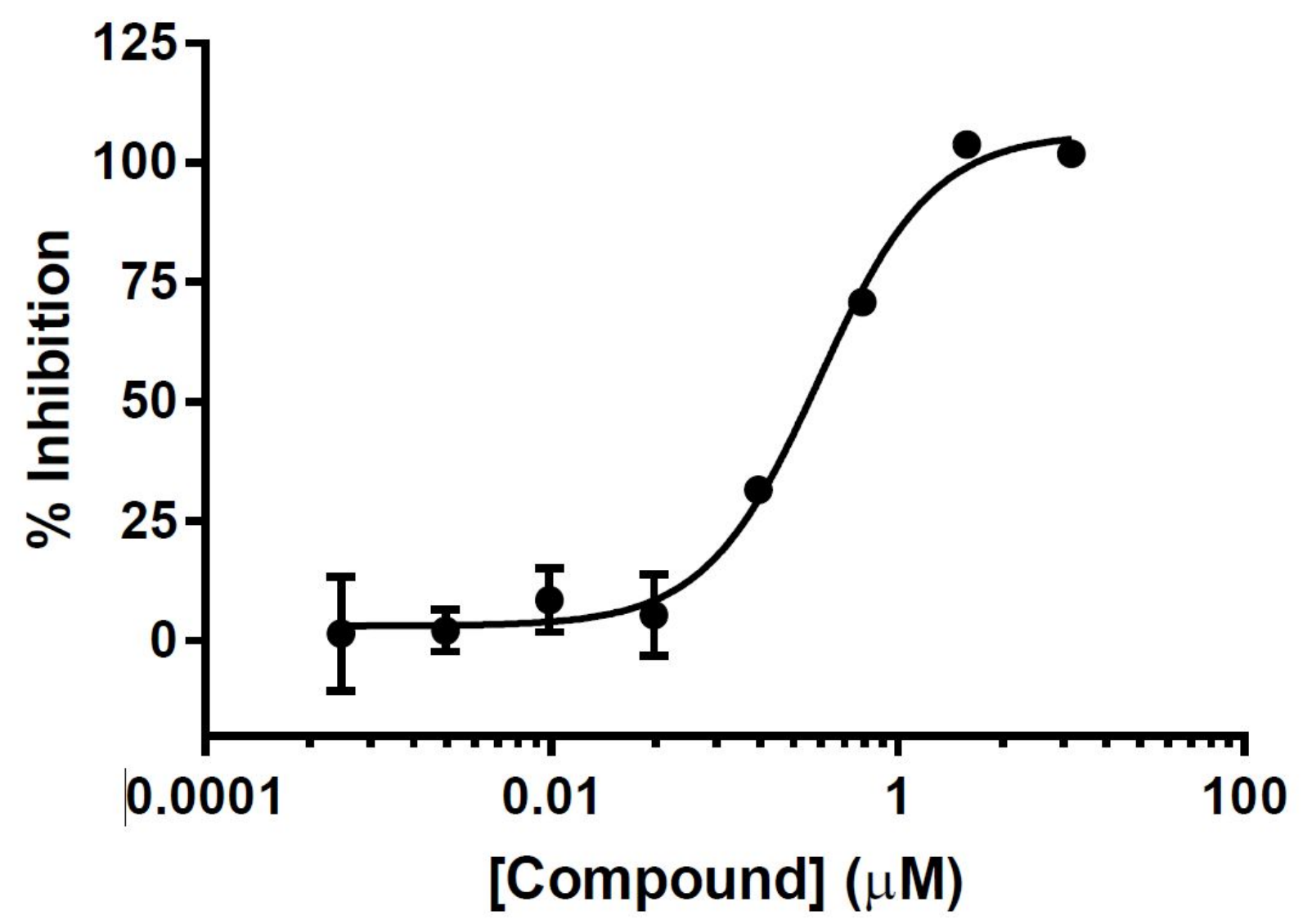

Figure S2. Inhibitory effects of 1 on rat $\beta$-NGF-induced neurite outgrowth in PC12 Cells (representative curve; error bars, standard deviation, $\mathrm{n}=2$ ).

In vitro evaluation of the effect of 1 in rat PC12 cell using label free CETSA assay. All the experimental protocols, assay development details, and screening information is reported elsewhere. ${ }^{4}$ Find below the details pertaining to 1 alone.

$T_{m}$ for assay development compounds

\begin{tabular}{|l|l|c|c|c|}
\hline Compound & Compound concentration & $\mathbf{T}_{\mathbf{m}}\left({ }^{\circ} \mathbf{C}\right)$ & $\mathbf{9 5 \%} \mathbf{C I}\left({ }^{\circ} \mathbf{C}\right)$ & $\mathbf{N} ; \mathbf{n}$ \\
\hline DMSO & & 49.7 & $44.1-52.9$ & $3 ; 6$ \\
\hline $\mathbf{1}$ & $10 \mu \mathrm{M}$ & 57.1 & $55.6-58-7$ & $3 ; 6$ \\
\hline
\end{tabular}



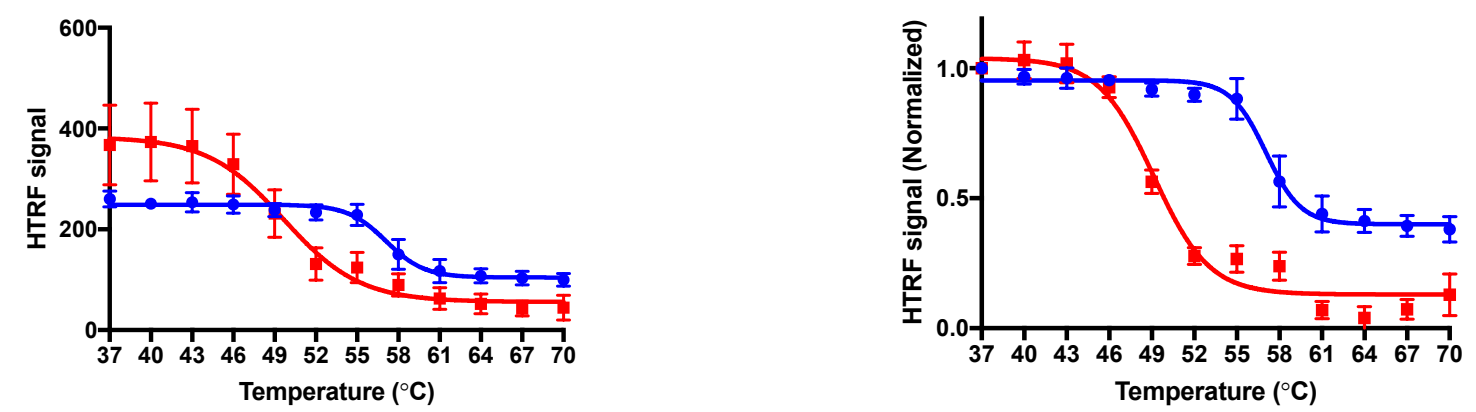

Melt and shift curves of assay development compound. The solid lines are the logistic curve fits to the data points. HTRF signal (left) from samples aliquoted and heated to temperatures from $37^{\circ} \mathrm{C}$ to $70^{\circ} \mathrm{C}$ treated with 1 (blue) or DMSO control (red) $(\mathrm{N}=3 ; \mathrm{n}=6)$. The HTRF signals (right) of the melt curves normalized to the individual raw signal at $37^{\circ} \mathrm{C}$.
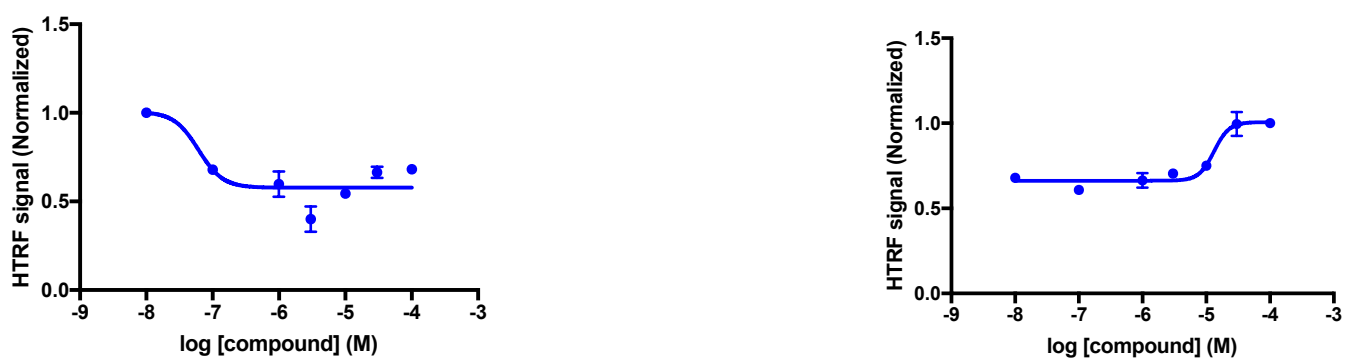

Dose response of 1 at $40^{\circ} \mathrm{C}$ (left, favoring kinase inactive conformation) and $52^{\circ} \mathrm{C}$ (right, favoring kinase active state).

$\mathrm{EC}_{50}$ value for the test compound

\begin{tabular}{|l|c|c|}
\hline Compound & $\mathbf{E C}_{\mathbf{5 0}} \mathbf{4 0}^{\circ} \mathbf{C}$ & $\mathbf{E C}_{\mathbf{5 0}} \mathbf{5 2}^{\circ} \mathbf{C}$ \\
\hline 1 & $61 \mathrm{nM}$ & $13 \mu \mathrm{M}$ \\
\hline
\end{tabular}


Table S1. Data collection, processing, and refinement statistics for $h$ TrkA...1 bound kinase complexa

\begin{tabular}{|c|c|c|}
\hline \multicolumn{2}{|l|}{ Wavelength $[\AA]$} & 0.9999 \\
\hline \multicolumn{2}{|l|}{ Detector } & PILATUS 6M \\
\hline \multicolumn{2}{|l|}{ Temperature $[\mathrm{K}]$} & 100 \\
\hline \multicolumn{2}{|l|}{ Space group } & $P 3_{1} 12$ \\
\hline \multicolumn{2}{|l|}{ Cell: a; b; c; $[\AA]$} & $\begin{array}{l}52.06 ; 52.06 ; \\
227.92\end{array}$ \\
\hline \multicolumn{2}{|l|}{$\alpha ; \beta ; \gamma ;\left[^{\circ}\right]$} & $90.0 ; 90.0 ; 120.0$ \\
\hline \multicolumn{2}{|l|}{ Resolution $[\AA]$} & $2.06(2.31-2.06)$ \\
\hline \multicolumn{2}{|l|}{ Unique reflections } & $21952(6279)$ \\
\hline \multicolumn{2}{|l|}{ Multiplicity } & $2.9(2.9)$ \\
\hline \multicolumn{2}{|l|}{ Completeness [\%] } & $97.9(97.7)$ \\
\hline \multicolumn{2}{|l|}{$\mathrm{R}_{\mathrm{svm}}[\%]$} & $4.0(44.3)$ \\
\hline \multicolumn{2}{|l|}{$R_{\text {meas }}[\%]$} & $4.9(53.9)$ \\
\hline \multicolumn{2}{|l|}{ Mean(I)/sd } & $18.3(3.08)$ \\
\hline \multirow{4}{*}{ Refinement statistics: } & Resolution $[\AA]]$ & $75.97-2.06$ \\
\hline & $\begin{array}{l}\text { Number of reflections } \\
\text { (working/test) }\end{array}$ & $20215 / 1729$ \\
\hline & $R_{\text {cryst }}[\%]$ & 19.9 \\
\hline & $\mathrm{R}_{\text {free }}[\%]^{\mathrm{d}}$ & 23.9 \\
\hline \multirow{3}{*}{ Total number of atoms: } & Protein & 2425 \\
\hline & Water & 110 \\
\hline & Ligand & 35 \\
\hline \multirow{3}{*}{$\begin{array}{l}\text { Deviations from ideal } \\
\text { geometry: }\end{array}$} & Bond lengths $[\AA]$ & 0.008 \\
\hline & Bond angles $\left[{ }^{\circ}\right]$ & 1.29 \\
\hline & Bonded B's $\left[\AA^{2}\right]^{\dagger}$ & 4.1 \\
\hline \multirow{3}{*}{ Ramachandran plot:9 } & Most favored regions [\%] & 93.3 \\
\hline & $\begin{array}{l}\begin{array}{l}\text { Additional allowed regions } \\
{[\%]}\end{array} \\
\end{array}$ & 6.3 \\
\hline & $\begin{array}{l}\text { Generously allowed } \\
\text { regions [\%] }\end{array}$ & 0.4 \\
\hline \multicolumn{2}{|c|}{ Data processing programs } & XDS \& XSCALE \\
\hline \multirow{2}{*}{\multicolumn{2}{|c|}{$\begin{array}{l}\text { Structure modeling \& refinement } \\
\text { PDB structure deposition code }\end{array}$}} & CCP4 \& COOT \\
\hline & & 6PL4 \\
\hline
\end{tabular}

a amino acids not defined by the electron density include residues 491-499, 609-611 and the side chains of residues $487,490,508,521,535-538,547-548,551,554-555$, $558-559,563,566,570,644,686,703,725,747,750,755,761,767,769-770$, and 775 .

b Swiss Light Source (SLS, Villigen, Switzerland)

c values in parenthesis refer to the highest resolution bin

${ }^{d}$ Test-set contains $7.9 \%$ of measured reflections

e root mean square deviations from geometric target values 
${ }^{f}$ calculated with MOLEMAN

9 calculated with PROCHECK
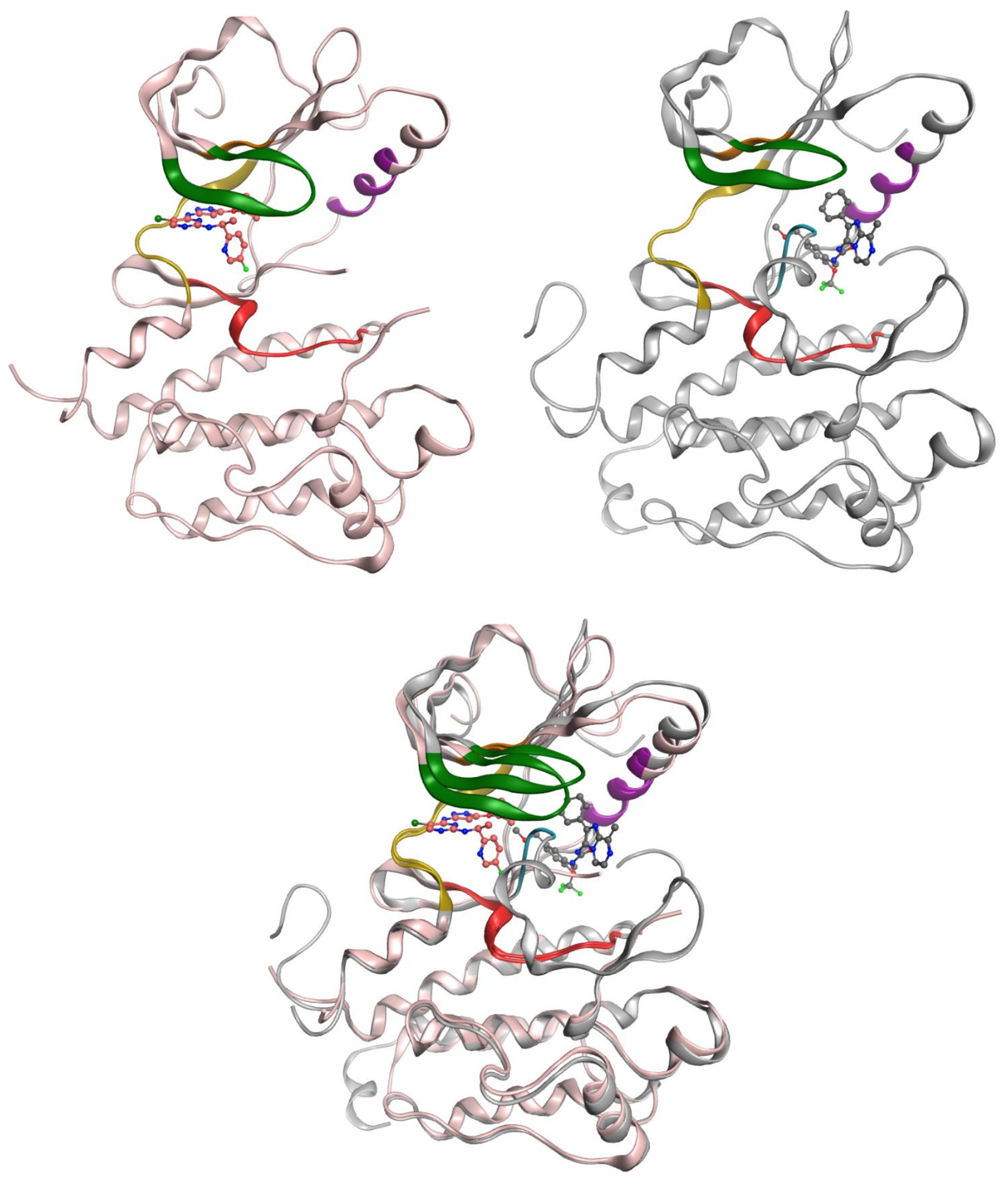
Figure S3. X-ray structure of $h$ TrkA...AZ-23 (top left) and $h$ TrkA...1 (top right) kinase domain complex with the superposed protein arrangement in the bottom. The inhibitors are shown in ball \& stick representation. The $2^{\circ}$ structure ribbon rendition depicts the hinge region is gold, the gly-rich flap in green, the $\alpha \mathrm{C}$-helix in magenta, the start of the $\mathrm{A}$ loop in cyan and the rest of the protein in either pink/grey.

The superposition of the inhibitor bound $h$ TrkA kinase domain $\mathrm{x}$-ray structures of an ATP competitive inhibitor like AZ-23 (PDB: 4AOJ) and the allosteric inhibitor, 1 (PDB: 6PL4), reveal the mutually exclusive binding pockets occupied by the two inhibitors (Fig. S3). Due to the residues of the activation loop occupying part of the ATP site, the Gly-rich loop is pushed a little upwards for the allosteric inhibitor bound kinase complex. 


\section{Animal Experiments}

All work was done in accordance with National Institutes of Health Guide to the Care and Use of Laboratory Animals, the Animal Welfare Act, and International Association for the Study of Pain Guidelines for the Use of Animals in Research, as well as subject to approval of the respective Institutional Animal Care and Use Committees. All activities involving animals occurred in an AAALAC-accredited vivarium.

\section{Ex vivo immunohistochemical detection of TrkA in the dorsal root ganglion and spinal cord of rats treated intra-articularly with monoiodoacetate (MIA).}

Adult, male Sprague-Dawley rats (200-250 g, Charles River, Wilmington, MA) served as experimental subjects. Animals were housed 2 per cage with food and water available ad libitum. Animals were kept on a 12:12 hour light-dark cycle. This study complied with all applicable animal welfare regulations related to the humane care and use of animals. The protocol was approved by the Zoetis Institutional Animal Care and Use Committee prior to initiation of the study. All work occurred at Zoetis (Kalamazoo, MI), an AALAC accredited facility.

Osteoarthritis was induced via administration of $2 \mathrm{mg}$ monosodium iodoacetate (MIA; Sigma) into the intra-articular space of the left stifle joint of each rat. Each rat was sedated with isoflurane (2.5-5\% in pure O2, Henry Schein, Dublin, $\mathrm{OH}$ ) and when the proper plane of anesthesia was achieved, the stifle joint was shaved and swabbed with alcohol followed by betadine swab. A sterile MIA solution $(40 \mathrm{mg} / \mathrm{mL})$ was prepared by mixing 5.0 $\mathrm{mL}$ of $0.9 \%$ sterile saline (B. Braun, Bethlehem, PA) to $200 \mathrm{mg}$ of MIA powder. Within 24 
hours of preparation, an injection of $50 \mu \mathrm{L}$ of MIA solution was administered via a $25 \mathrm{G}$ needle into the intra-articular space on study Day 0.

Fourteen days after MIA induction, the rats were humanely euthanized via low-flow $\mathrm{CO}_{2}$ asphyxiation. Once death was confirmed, the skin and muscle were dissected from the spinal column. The lumbar region of the spinal column was opened to expose the dorsal root ganglion (DRG) and spinal cord. The spinal cord and the DRGs of the affected side were removed and fixed in $10 \%$ formalin for 24 hours then dehydrated through $70 \%, 95 \%$, and $100 \%$ ethanol. The dehydrated tissues were cleared in xylene, infiltrated in paraffin, embedded in paraffin blocks, and sectioned onto slides at $4 \mu \mathrm{m}$. All successive steps were completed using Leica Bond ${ }^{\mathrm{TM}} \mathrm{RX}$ automation. Paraffin was removed from slides by Bond ${ }^{\mathrm{TM}}$ Dewax Solution and rehydrated through a succession of decreasing concentrations of ethanol and equilibrated in water. Antigen retrieval was performed by incubating slides in Bond ${ }^{\mathrm{TM}}$ Epitope Retrieval Solution 1 for 20 minutes at $100^{\circ} \mathrm{C}$. Endogenous peroxidase activity was blocked by incubating slides in hydrogen peroxide for 5 minutes, and non-specific protein binding was blocked using UltraVision Protein Block (ThermoFisherScientific) for 10 minutes. Sections were incubated in TrkA Polyclonal Antibody (Bioss) at 1:200 for 15 minutes, washed, and incubated in polymer anti-rabbit Poly-HRP-lgG for 8 minutes. Signal was generated by incubating slides for 10 minutes in 3,3'-diaminobenzidine (DAB), and counterstained with hematoxylin for 5 minutes. All reagents not specifically detailed above are included in the Leica Bond ${ }^{\mathrm{TM}}$ Polymer Refine Detection Kit. Slides were removed, dehydrated in ethanol, and coverslipped with Leica Micromount Mounting Media. 
To evaluate the expression and internalization of the TrkA receptor in the rat MIA model of osteoarthritis, immunohistochemistry of DRGs and spinal cord explants was conducted ( $\mathrm{N}=10$ rats). The most abundant TrkA staining was visualized in the neuronal cell bodies of the dorsal root ganglion, with stain intensity directly correlating to the amount of protein in the tissue. Staining intensity was variable throughout the ganglion, although neuronal cell bodies were globally positive for TrkA, with uniform staining present intracellularly in the nucleus and cytoplasm. Satellite cells and individual axons in the peripheral nerve presented little or no TrkA labeling (Fig. S4a-b). The lumbar section of the spinal cord exhibited elevated staining of TrkA in the dorsal horn of the grey matter. Staining of neuronal cells bodies and, to a lesser extent, neuropils was present. Although more variable, neuroglial cells showed both nuclear and cytoplasmic staining, and about $30 \%$ of ependymal cells demonstrated diffuse intracellular staining (Fig. S4c). Overall, there appears to be less staining observed in spinal cord tissue than in the dorsal root ganglion. This strongly suggests internalization of the target in the efficacy model.

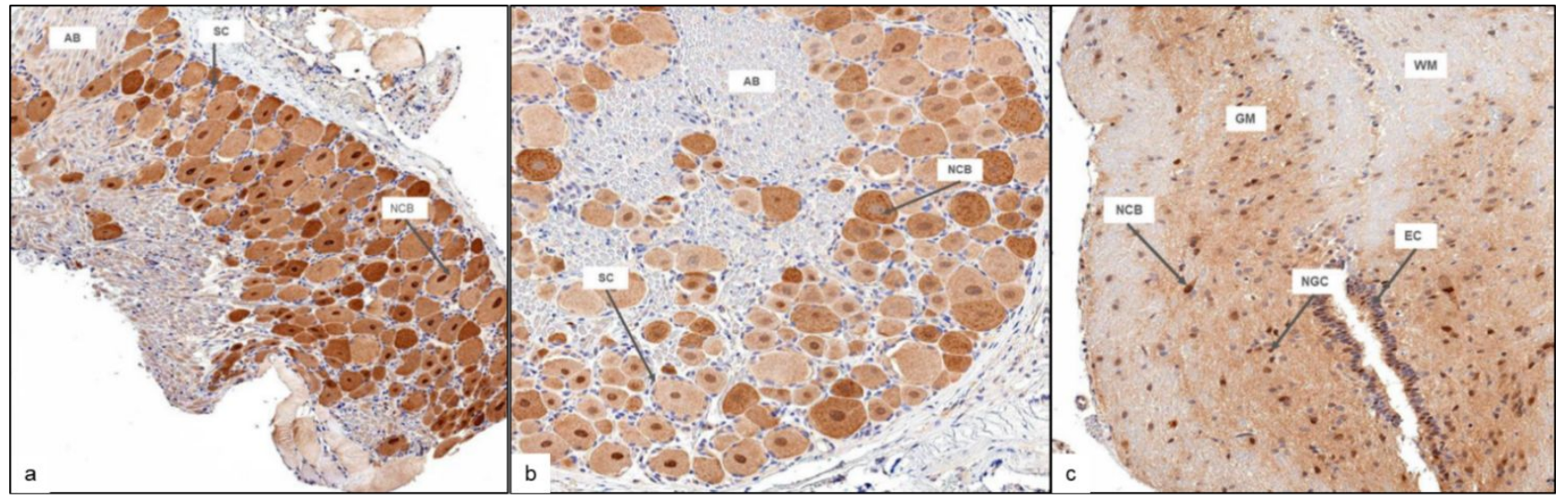

Figure S4. Immunohistochemical staining of TrkA receptors on tissues isolated from intra-articular MIA treatment of rats. Internalization of the TrkA receptor is represented by the dark brown staining. $\mathbf{a}$ and $\mathbf{b}$. Rat DRG stained for TrkA (DAB) and hematoxylin. IHC for TrkA shows labeling predominant in neuronal cell bodies within the DRG. Labeling intensity varied between cells but was uniform within the nucleus and cytoplasm 
of a single cell. Satellite cells were negative for TrkA and individual axons within axon bundles had minimal to negative labeling for TrkA. NCB $=$ Neuron Cell Body, $S C=$ Satellite Cells, $A B=$ Axon Bundle. 20x. c. Rat lumbar spinal cord Trk A labeling (DAB) and hematoxylin. IHC for TrkA shows increased labeling and intensity of cell bodies in the dorsal horn of the grey matter compared to the white matter. Labeling was present within neuronal cell bodies as well as more diffusely throughout the neuropil in the grey matter. Neuroglial cells showed variable nuclear and cytoplasmic staining and ependymal cells had diffuse cytoplasmic labeling with nuclear labeling in a subset of cells (approx. 30\%). NCB=Neuron Cell Body, GM=Grey Matter, WM=White matter, $\mathrm{EC}=$ Ependymal Cells, NGC= neuroglial cells. 20x. 


\section{Effect of 1 in a monoiodoacetate (MIA) rat model of osteoarthritis}

Effect of 1 on nociception. The MIA rat model of OA has been shown to be an appropriate model for the evaluation of TrkA substrate. Adult, male Sprague-Dawley rats ( $N=30 ; 200-250$ g, Envigo, Madison, WI) were used in the behavioral experiments. Animals were housed 2 per cage with food and water available ad libitum. All work occurred at American Preclinical Services (Minneapolis, MN) in an environmentally controlled AAALAC accredited facility. This study complied with all applicable animal welfare regulations related to the humane care and use of animals. The protocol was approved by the American Preclinical Services Institutional Animal Care and Use Committee prior to the initiation of the study. Animals were kept on a 12:12 hour light-dark cycle with experimental recordings at the same times each day.

OA was induced via administration of $2 \mathrm{mg} \mathrm{MIA} \mathrm{(Sigma,} \mathrm{St.} \mathrm{Louis,} \mathrm{MO)} \mathrm{into} \mathrm{the} \mathrm{intra-articular}$ space of the left stifle joint of each rat. Each rat was sedated with isoflurane (2. $5-5 \%$ in pure $\mathrm{O}_{2}$, Henry Schein, Dublin, $\mathrm{OH}$ ) and when the proper plane of anesthesia was achieved, the stifle joint was shaved and swabbed with alcohol followed by betadine swab. A sterile MIA solution (40 $\mathrm{mg} / \mathrm{mL}$ ) was prepared by mixing $5.0 \mathrm{~mL}$ of $0.9 \%$ sterile saline (B. Braun, Bethlehem, PA) to 200 mg of MIA powder. Within 24 hours of preparation, an injection of $50 \mu \mathrm{L}$ of MIA solution was administered via a $25 \mathrm{G}$ needle into the intra-articular space on study Day -14.

On Day 0, animals were randomized to three treatment groups based on pre-treatment, postMIA joint compression thresholds (JCTs). Animals were ranked by percent difference scores from lowest to highest. Treatments were assigned randomly within stratified sub-groups such that 
there were no significant differences between treatment groups prior to treatment administration. Each treatment group consisted of 10 animals.

Vehicle was administered via oral gavage at a dose volume of $1 \mathrm{~mL} / \mathrm{kg}$ (T01). 1 (10 mg/kg, PO) was prepared in 5\% 1-methyl-2-pyrrolidinone and 95\% PEG 200 and administered via oral gavage at a volume of $1 \mathrm{~mL} / \mathrm{kg}$ either qd (T02) or BID (T03). $\mathbf{1}$ (qd or BID) or vehicle (BID) administration occurred daily for 14 days. For the BID groups, the second administration occurred approximately 10 hours after the morning administration. For all groups, a final dose administration occurred in the morning on Day 15.

Behavior testing for mechanical hyperalgesia was performed prior to MIA inductions on Day -14 and on Days $0,7,14$, and 16 . On Days 0,7 , and 14, behavioral testing occurred prior to dose administration, and 2, 5, and 8 hours after dose administration. Additionally, behavioral testing occurred on Day 16, 24 hours after final dose administration.

Mechanical hyperalgesia was measured using a digital Randall-Selitto device (dRS; IITC Life Sciences). Animals could acclimate to the testing room for a minimum of 15 minutes before testing. Animals were placed in a restraint sling that suspended the animal, leaving the hind limbs available for testing. The stimulus was applied to the knee joint by a blunt tip and pressure applied gradually over approximately 10 secs. JCT values were recorded at the first observed nocifensive behavior (vocalization, struggle, or withdrawal). One reading per joint was taken at each time point, and a maximum stimulus cutoff of $500 \mathrm{~g}$ was used to prevent injury to the animal. The mean $( \pm S E M)$ was determined for each joint for each treatment group at each time point. Data were normally distributed and analyzed using GraphPad Prism v7.03 (GraphPad 
Software Inc.) with significance set at $P<0.05$. To determine the effect of MIA on JCTs, the ipsilateral and contralateral JCTs for the vehicle-treated animals were analyzed using a repeatedmeasure two-way ANOVA followed by Bonferroni's multiple comparisons. The effects of 1 on JCTs were determined using a repeated-measures two-way ANOVA followed by Tukey's multiple comparisons. For the effect of vehicle or 1 on pretreatment baselines, data were analyzed using a linear regression analysis to determine if slope was significantly different from zero.

\section{Reduction of pain in chronic osteoarthritis model}

On Day -14, MIA was injected into the left intra-articular space, producing OA-induced pain, as demonstrated by significant decreases in JCTS in the ipsilateral joints compared to the contralateral joints of the vehicle-treated animals (interaction: $F_{(13,234)}=7.483, P<0.0001$; time: $F_{(13,234)}=5.564, P<0.0001$; ipsilateral vs contralateral: $F_{(1,18)}=302.5, P<0.0001$; subjects: $F_{(13,}$ 234) $=2.557, \mathrm{P}<0.001$ ). This effect was observed over the course of the entire study (Fig. S5). Statistical analysis of the effect of 1 on JCT revealed a significant effect of time $\left(F_{(12,324)}=9.032\right.$; $P<0.0001)$, treatment $\left(F_{(2,22)}=6.08 ; P<0.01\right)$ and subjects $\left(F_{(27,324)}=5.781 ; P<0.0001\right)$, but no interaction $\left(F_{(24,324)}=1.382 ; P=0.11\right)$. 


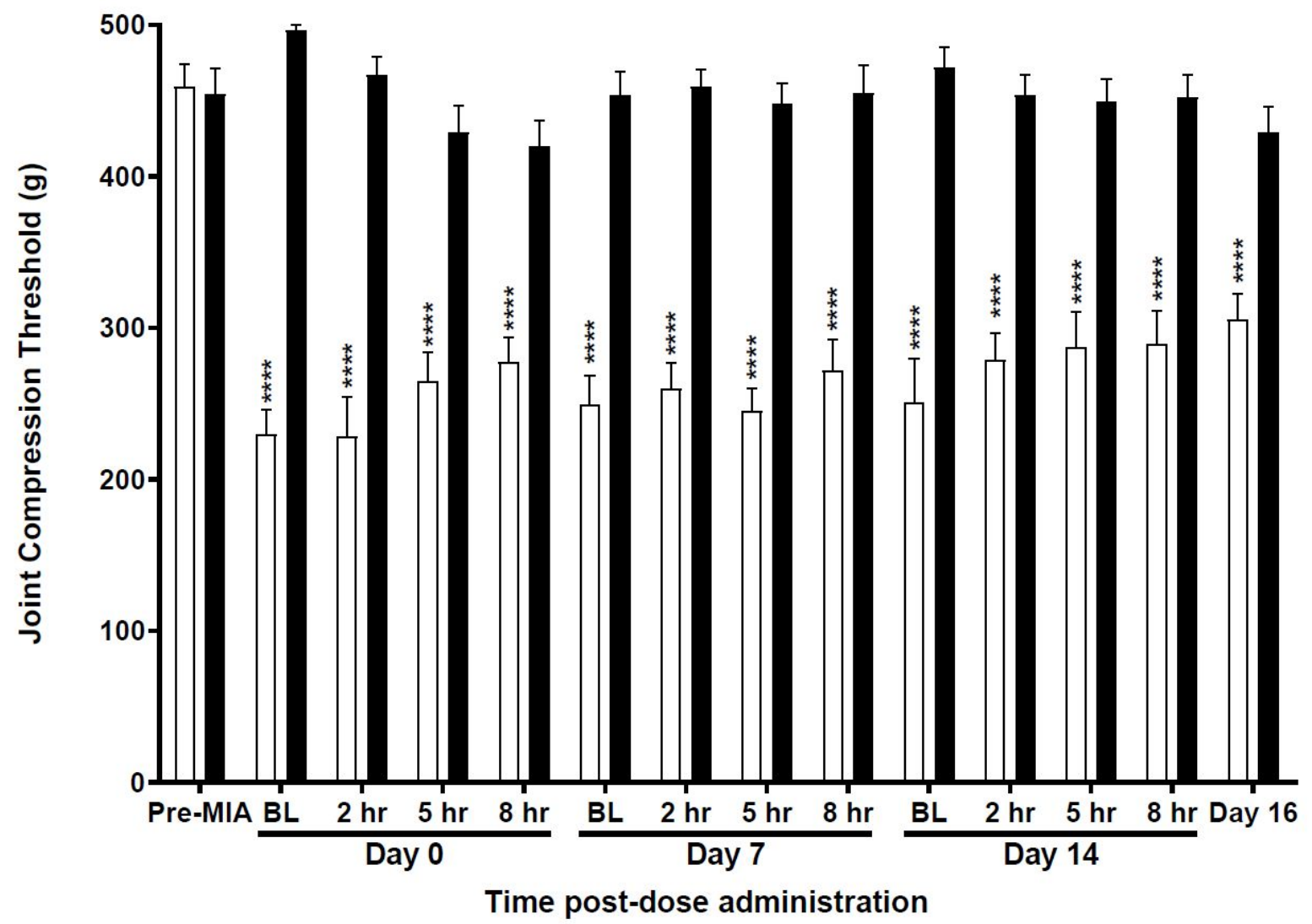

Figure S5. Effect of MIA on joint compression thresholds (mean \pm SEM) for ipsilateral and contralateral joints in vehicle-treated animals $(\mathrm{N}=10)$. Pre-MIA recordings were taken in naïve animals prior to MIA induction on Day -14 . On Day 0 , treatment with vehicle began. There was a significant decrease in JCT of the ipsilateral joint (open bars) compared to the contralateral joint (closed bars) at each post-MIA induction timepoint $\left({ }^{* * *} P<0.0001\right)$. This represents a successful induction of a painful response in this model.

On Day 0, 1 dosed qd produced a significant increase in JCT at 2 hours post-dose. On Day 7, both treatments (qd, BID) of 1 produced significant increases in JCTs 5 hours post-dose. On Day 14, qd treatment of 1 produced a significant effect 2 hours post-dose, and BID treatment produced significant effects at 5- and 8-hours post-dose. Interestingly, BID treatment also produced a significant increase in JCT at BL measurements prior to treatment administration. Finally, on Day 16, 24 hours following the final dose of $\mathbf{1}$, there was a significant increase in JCTs for the qdtreated group (Fig. S6). 

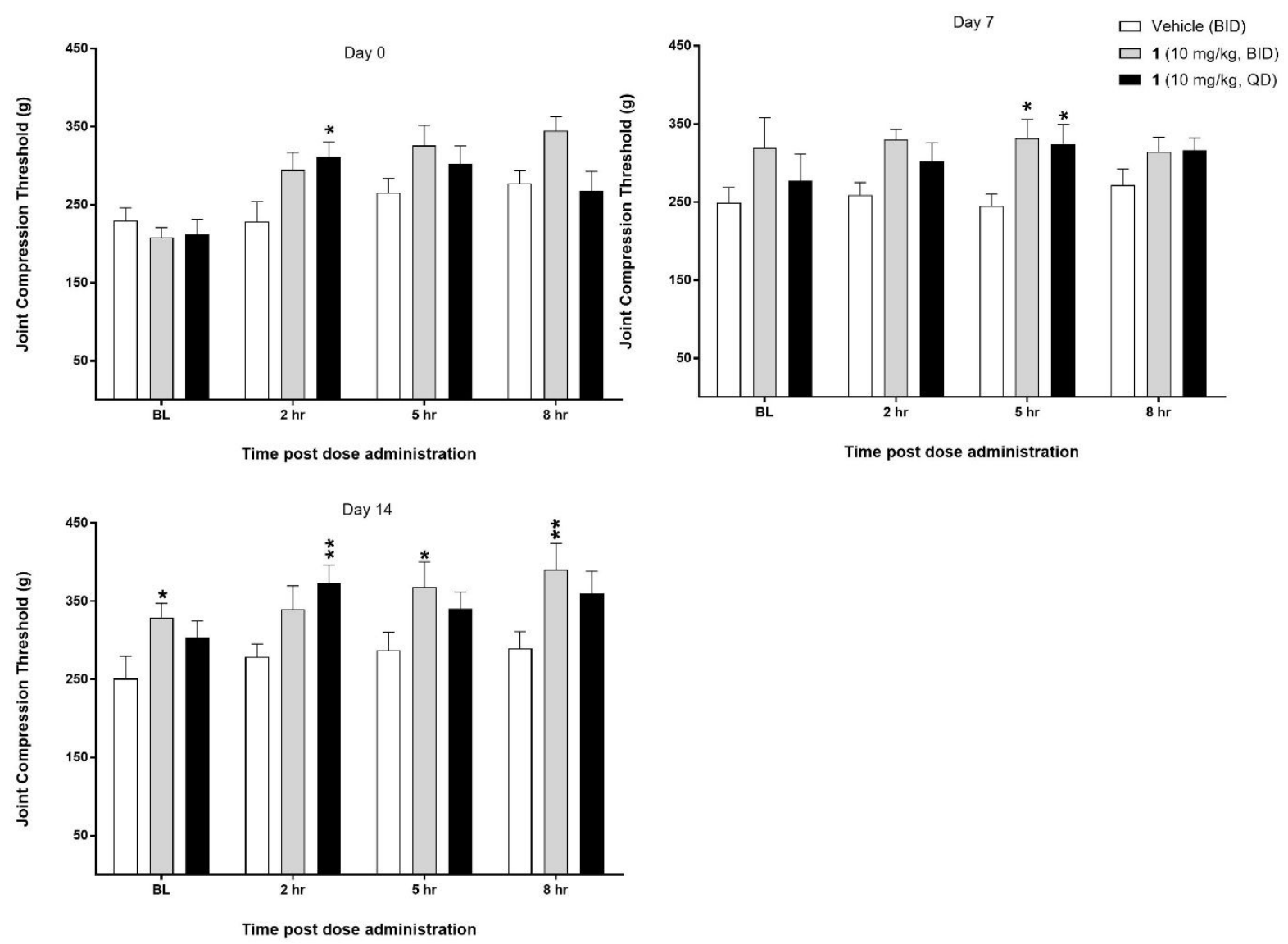

Figure S6. Joint compression threshold (mean \pm SEM) over time for $q d$ and BID administration of 1 in a rat MIA model ( $\mathrm{N}=10$ rats/treatment). Animals were injected with MIA on Day -14 and treatment with either vehicle or 1 began on Day 0 continuing through Day 15. Baseline (BL) recordings occurred immediately prior to the AM dose administration. JCTs measured on Day 16 occurred 24 hours after the last administration of vehicle or 1. Significance of effects of 1 treatment ( $q d$ or BID administration) compared to vehicle-treated animals was calculated at each time point using a two-way repeatedmeasures ANOVA followed by a Tukey's multiple comparisons ( ${ }^{*} P<0.05 ;{ }^{* *} P<0.01$ ).

Due to the significant effect of BID dosing of 1 on the pre-treatment JCT BL for Day 14, a linear regression analysis of only the pre-treatment JCT BL was performed to determine if the slope of these lines was significantly different from zero, signifying an increase in JCTs over the course of the experiment. Both treatment groups for 1 ( $\left.q d: F_{(1,28)}=6.5, P<0.01 ; B I D: F_{(1,28)}=9.975, P<0.05\right)$ showed an increase in pre-treatment baselines across the entire study that were significantly 
different from zero, but vehicle treatment did not produce a similar effect $\left(F_{(1,28)}=0.4725\right.$, $\mathrm{P}=0.4975$; Fig. S7). None of the treatments had any statistically significant effect on the contralateral limb, suggesting any effect was a direct result of altering the pain response induced by intra-articular MIA. Additionally, qd and BID doses were not significantly different.

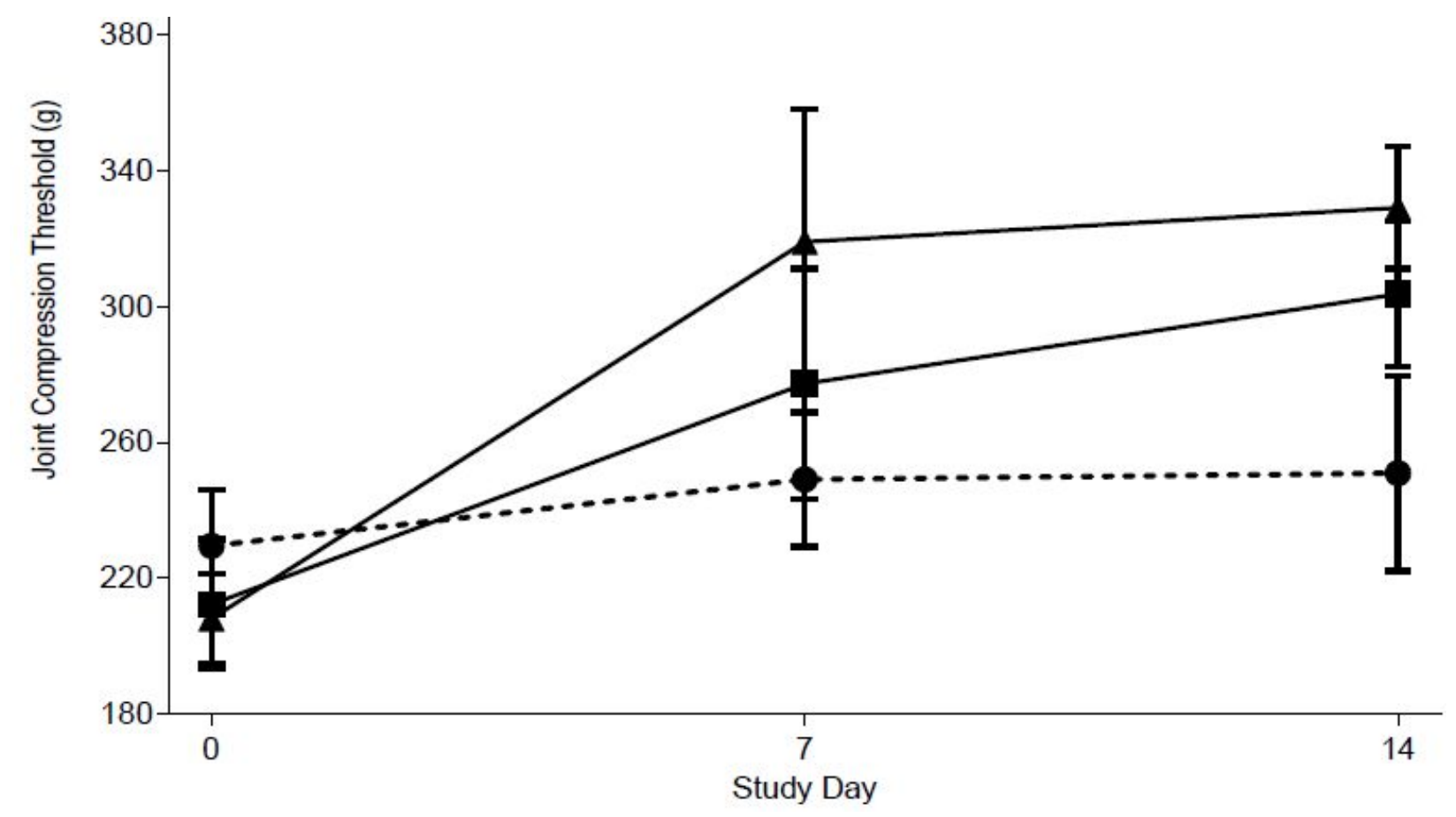

Figure S7. Mean SEM ipsilateral JCTs in rats following MIA injection in vehicle (filled circle) and $10 \mathrm{mg} / \mathrm{kg}$ of 1 treated (filled triangle [BID]; filled square $[q d]$ ) animals at baseline, prior to the AM dose. At day 0 , all animals were vehicle- and test article naïve ( $\mathrm{N}=10$ /group). 


\section{References}

1. Blake, J.F.; Brandhuber, B. J.; Haas, J.; Newhouse, B.; Thomas, A. A.; Winski, S. L. $\mathrm{N}$-(Arylalkyl)-N'-pyrazolyl-urea, thiourea, guanidine and cyanoguanidine compounds as TrkA kinase inhibitors and their preparation. WO2014/078331A1, 2014.

2. Allen, S.; Brandhuber, B. J.; Condroski, K. R.; Huang, L.; Kercher, T.; Winski, S. L. Bicyclic heteroaryl urea, thiourea, guanidine and cyanoguanidine compounds as TrkA kinase inhibitors and their preparation. WO2014/078408A1, 2014.

3. Greene, L. A.; Tischler, A. S. Establishment of a noradrenergic clonal line of rat adrenal pheochromocytoma cells which respond to nerve growth factor. Proc. Natl. Acad. Sci. USA., 1976, 73, 2424-2428.

4. Subramanian, G.; Johnson, P. D.; Zachary, T.; Roush, N.; Zhu, Y.; Bowen, S. J.; Janssen, A.; Duclos, B. A.; Williams, T.; Javens, C.; Dekki-Shalaly, N.; Martinez-Molina, D.; Wittwer, A. J.; Hirsch, J. L. Deciphering the Allosteric Binding Mechanism of the Human Tropomyosin Receptor Kinase A (hTrkA) Inhibitors. ACS Chem. Biol., 2019, 14, 1205-1216. 